\title{
Normal ferroelectric to relaxor behavior in laser ablated Ca-doped barium titanate thin films
}

\author{
P. Victor, R. Ranjith, and S. B. Krupanidhi ${ }^{\text {a) }}$ \\ Materials Research Center, Indian Institute of Science, Bangalore 560 012, India
}

\begin{abstract}
$\mathrm{Ba}_{1-x} \mathrm{Ca}_{x} \mathrm{TiO}_{3}$ thin films ( $x=0.05$ to 0.17 ) were deposited on Pt-coated Si substrates using a pulsed excimer laser ablation technique. X-ray diffraction and scanning electron microscope studies of the $\mathrm{Ba}_{1-x} \mathrm{Ca}_{x} \mathrm{TiO}_{3}$ targets exhibit a polycrystalline nature and thin films also show the same but with a significant orientation along the (111) direction. Secondary ion mass spectrometer analysis reveals the presence of a sharper interface existing at the thin film substrate. The dielectric phase transition temperature of $\left(\mathrm{Ba}_{1-x} \mathrm{Ca}_{x}\right) \mathrm{TiO}_{3}$ targets were sharp and the transition temperature was found to decrease from $140{ }^{\circ} \mathrm{C}$ to $110^{\circ} \mathrm{C}$ with an increase in the values of $x(x>0.05$ at. \%). The laser ablated $\mathrm{Ca}$-doped $\mathrm{BaTiO}_{3}$ thin films deposited at 100 mTorr exhibited a higher dielectric constant, lower dielectric loss, and an anomalous decrease in phase transition was observed. The anomalous phase transition decrease was ascribed to the occupancy of the $\mathrm{Ca}^{2+}$ in $\mathrm{The}^{\mathrm{Ti}^{4+}}$ site. There was a cross over from the sharp to diffused phase transition for a higher composition of $\mathrm{Ca}(>9$ at. \%) in $\mathrm{BaTiO}_{3}$ thin films. The diffuse transition behavior might be due to the larger number of the $\mathrm{Ca}^{2+}$ ions occupying the $\mathrm{Ti}^{4+}$ site, eventually introducing larger compositional and structural disorder and this occupancy leads to the generation of oxygen vacancies. The activation energy obtained from impedance spectroscopy was $1.05 \mathrm{eV}$, and was attributed to the oxygen vacancy motion.
\end{abstract}

\section{INTRODUCTION}

Ferroelectric materials are gaining importance in technology especially in the areas of the memory storage devices, ${ }^{1,2}$ microelectromechanical systems, ${ }^{3}$ multilayer ceramic capacitors, ${ }^{4}$ and recently in the areas of optoelectronic devices. ${ }^{5}$ Specifically, barium titanate and isovalent substituted $\mathrm{BaTiO}_{3}$ are the promising candidates for potential use in the applications of microwave communications and optoelectronic devices. Barium calcium titanate (BCT) crystals show promising applications in advanced laser systems, optical interconnects, and optical storage devices. ${ }^{6}$ Calcium acts as a reduction inhibitor in $\mathrm{BaTiO}_{3}$ and reduces the possibility of formation of the unwanted hexagonal phase. $\mathrm{Ba}_{(1-x)} \mathrm{Ca}_{x} \mathrm{TiO}_{3}$ ceramics ( $x=0$ to 22 at. \%) prepared via a conventional solid-state reaction technique was observed to be ferroelectric at room temperature with point symmetry of $4 \mathrm{~mm} .{ }^{7,8}$ The dielectric phase transition temperature $(\sim 140-$ $120^{\circ} \mathrm{C}$ ) from the tetragonal to cubic phase was found to marginally affect the substitution of the $\mathrm{Ca}^{2+}$ in $\mathrm{Ba}^{2+}$ site of the $\mathrm{Ba}_{1-x} \mathrm{Ca}_{x} \mathrm{TiO}_{3}$ ceramics. In the case of $\mathrm{Ca}^{2+}$ occupying the $\mathrm{Ti}^{4+}$ site, the transition temperature was found to decrease drastically to $320 \mathrm{~K}$ for $\mathrm{BaCa}_{x} \mathrm{Ti}_{(1-x)} \mathrm{O}_{(3-x)}(x$ $=0.15$ ) ceramics. ${ }^{9}$ There are various routes adopted to prepare the BCT ceramics and, interestingly, the BCT is strongly processing dependent especially on the occupancy of $\mathrm{Ca}^{2+}$ ions in the $\mathrm{Ti}^{4+}$ site of the $\mathrm{BaTiO}_{3}$. There are questions yet to be clearly answered on the possibility of $\mathrm{Ca}^{2+}$ occupying the $\mathrm{Ti}^{4+}$ site because of their differences in the

\footnotetext{
a) Author to whom correspondence should be addressed; electronic mail: sbk@mrc.iisc.ernet.in
}

ionic radii and valences, in spite of there being sufficient experimental evidence in literature based on Raman spectroscopy, ${ }^{10}$ neutron diffraction, ${ }^{11}$ and conductivity ${ }^{9}$ studies. Based on the existing reports in BCT ceramics, the occupancy of $\mathrm{Ca}^{2+}$ in the $\mathrm{Ti}^{4+}$ site gives rise to doubly charged acceptor centers $\mathrm{Ca}_{\mathrm{Ti}}^{\prime \prime}$.

Han et al., ${ }^{12}$ Zhang et al. ${ }^{13}$ and Hennings et al. ${ }^{14}$ suggested that there is a probability of $\mathrm{Ca}^{2+}$ occupying the $\mathrm{Ti}^{4+}$ site in the $\mathrm{BaTiO}_{3}$ lattice, provided the atomic concentration ratio of $(\mathrm{Ba}+\mathrm{Ca}) / \mathrm{Ti}>1$. This ratio leads to excess barium, thereby forcing $\mathrm{Ca}^{2+}$ to occupy the $\mathrm{Ti}^{4+}$ site and eventually leading to a drastic decrease in the dielectric phase transition temperature. Zhuang et al. ${ }^{15}$ proposed that the occupancy of $\mathrm{Ca}^{2+}$ in the $\mathrm{Ti}^{4+}$ site will create a compressional stress and eventually leads to the distortion of the lattice in $\mathrm{BaTiO}_{3}$.

There exist very few reports on BCT thin films in open literature and $\mathrm{BCT}$ is considered to be one of the foremost potential candidates for the electro-optic modulators and memory devices. Hence, in this article, we report on the growth of Ca-doped barium titanate thin films using a pulsed laser ablation technique and analyzed its structural, dielectric, and dielectric phase transitions in detail.

\section{EXPERIMENT}

$\mathrm{Ba}_{(1-x)} \mathrm{Ca}_{x} \mathrm{TiO}_{3}$ targets $[x=0.05$ (denoted as BCT5C), $0.08,0.10$ (BCT12C), 0.13 and 0.15$]$ were prepared via conventional solid-state reaction technique. High-purity starting powders of $\mathrm{BaCO}_{3}, \mathrm{TiO}_{2}$, and $\mathrm{CaCO}_{3}$ were weighed in stoichiometric proportion, ball milled for $10 \mathrm{~h}$, dried, and calcined at $1100^{\circ} \mathrm{C}$ for $3 \mathrm{~h}$. The calcined powders were pressed at $100 \mathrm{kN} / \mathrm{cm}^{2}$ into a $15 \mathrm{~mm}$ diameter disk-shaped pellet and 
the pellets were sintered at $1400{ }^{\circ} \mathrm{C}$ for $4 \mathrm{~h}$. The densities of the targets were $96 \%$ and the targets were used for the laser ablation. The BCT thin films were deposited on the Pt(111)coated Si substrate using a KrF excimer laser ablation technique (Lambda Physik, Germany, $248 \mathrm{~nm}$ ). The substrate temperature during the deposition was maintained at $650{ }^{\circ} \mathrm{C}$, with the laser fluence maintained at $3 \mathrm{~J} / \mathrm{cm}^{2}$ and substratetarget distance at $3.5 \mathrm{~cm}$. The base pressure were initially brought down to $1 \times 10^{-6}$ Torr and prior to the deposition, high-purity oxygen gas was introduced into the chamber and the deposition were carried at 100 mTorr for all the compositions of $\mathrm{Ba}_{1-x} \mathrm{Ca}_{x} \mathrm{TiO}_{3}$ targets. The in situ grown thin films and targets were structurally characterized by $\mathrm{x}$-ray diffraction [(XRD) Scintag XDS 2000]. The composition and distribution of the elements in thin films across the thickness were identified using energy dispersive analysis (Oxford Instruments) and secondary ion mass spectroscopy (SIMS), respectively. The surface morphology and cross section were analyzed using scanning electron microscope (SEM). Circular gold dots of $500 \mu \mathrm{m}$ diameter were deposited by thermal evaporation for the top electrodes $(\mathrm{Au} / \mathrm{BCT} / \mathrm{Pt}$ configuration). The electrode annealing was carried out at $325^{\circ} \mathrm{C}$ for 15 min and the metal-ferroelectric-metal (MFM) capacitor was used for the electrical characterization. Polarization hysteresis was analyzed using a RT-66A ferroelectric test system (RT 66A, test pulse width of $8 \mathrm{~ms}$ ). Dielectric and capacitance-voltage $(C-V)$ measurement was measured using a programmable Keithley LCZ 3330 meter (frequencies ranging from 0.1 to $100 \mathrm{kHz}$ at an oscillating amplitude of $100 \mathrm{mV}$ ) coupled with a Keithley 230 voltage source. All of the measurements on MFM capacitors were carried out at a temperature ranging from $200 \mathrm{~K}$ to $550 \mathrm{~K}$.

\section{RESULTS}

\section{A. Structural determination}

Figure 1 shows the XRD of the $\mathrm{Ba}_{(1-x)} \mathrm{Ca}_{x} \mathrm{TiO}_{3}$ targets (denoted as BCT) and these patterns show a polycrystalline nature with distinct tetragonal splitting at (002/200). The distinct tetragonal splitting is observed for the lower concentration of $x$ in the $\mathrm{Ba}_{1-x} \mathrm{Ca}_{x} \mathrm{TiO}_{3}$ targets and the tetragonal splitting merges into a single peak for $x>0.21$ eventually leading to the cubic phase at room temperature. There were additional peaks observed for the higher composition of $\mathrm{Ca}(x>0.13)$ in $\mathrm{Ba}_{1-x} \mathrm{Ca}_{x} \mathrm{TiO}_{3}$ targets, showing the evolution of secondary phases $\left(\mathrm{Ca}\right.$-rich $\mathrm{BaTiO}_{3}$ phase and is denoted as \# in the Fig. 1) and these peaks grow stronger with higher $\mathrm{Ca}$ content. Figure 2 shows the calculated $c / a$ ratio plotted as a function of the $x$ in the $\mathrm{Ba}_{1-x} \mathrm{Ca}_{x} \mathrm{TiO}_{3}$ targets. The $c / a$ ratio was observed to decrease with an increase in the incorporation of the $\mathrm{Ca}$ dopant $(\mathrm{Ca}>5$ at. \%) in the lattice site of the $\mathrm{BaTiO}_{3}$ targets. The lattice constant in the unit cell is observed to shrink with the increase in $\mathrm{Ca}^{2+}$ ions at the $\mathrm{Ba}^{2+}$ site, due to the smaller ionic radii of $\mathrm{Ca}^{2+}$ over $\mathrm{Ba}^{2+}$. It appears that the replacement of $a^{2+}$ with smaller $\mathrm{Ca}^{2+}$ "tightens" the structure making it difficult to remove the oxygen from the lattice and renders it more favorable to fill the extrinsic oxygen vacancies. There is an increase in the

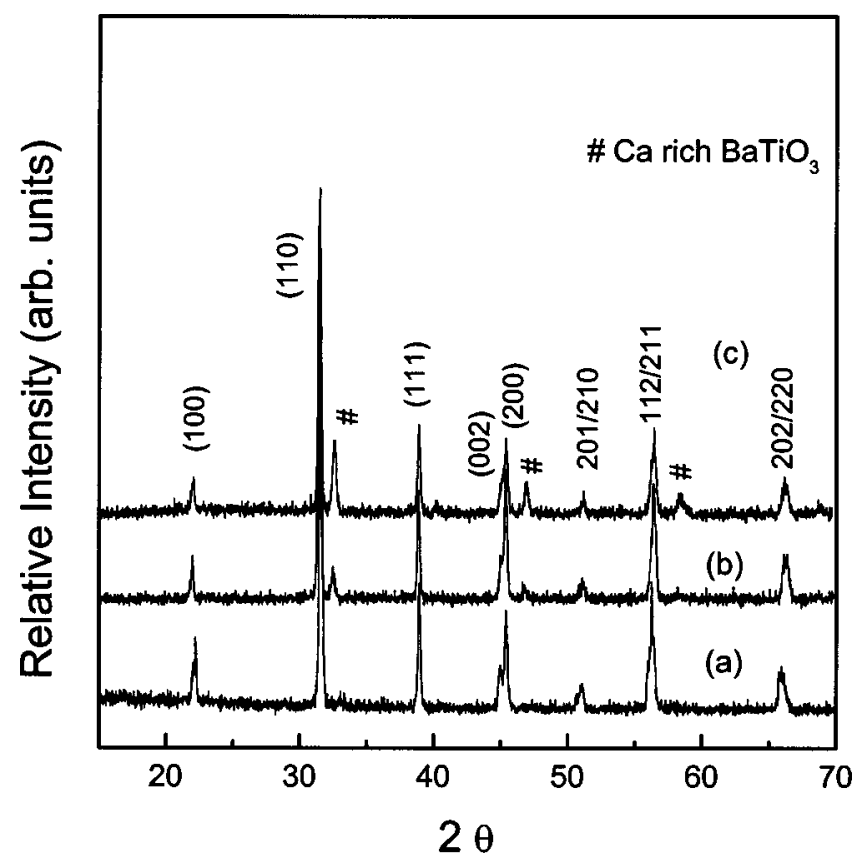

FIG. 1. The XRD pattern of the $\mathrm{Ba}_{(1-x)} \mathrm{Ca}_{x} \mathrm{TiO}_{3}$ targets: (a) $\mathrm{Ba}_{0.95} \mathrm{Ca}_{0.05} \mathrm{TiO}_{3}$, (b) $\mathrm{Ba}_{0.88} \mathrm{Ca}_{0.12} \mathrm{TiO}_{3}$, and (c) $\mathrm{Ba}_{0.85} \mathrm{Ca}_{0.15} \mathrm{TiO}_{3}$.

broadening of the diffracted peaks and a significant decrease in the grain size observed with increasing the $\mathrm{Ba}_{1-x} \mathrm{Ca}_{x} \mathrm{TiO}_{3}$ targets.

The XRD of the BCT thin films deposited on a Pt(111)coated Si substrate is shown in Fig. 3. All of the thin films exhibited the (111) orientation with little orientation along (110), and the orientations of the thin films can be tailored accordingly to the processing conditions. Kim et al. ${ }^{16}$ reported on the tailoring of the orientation of the laser ablated $\mathrm{BaTiO}_{3}$ thin films on Si substrates, based on the growth pressure. The evolution of the secondary phases was observed for

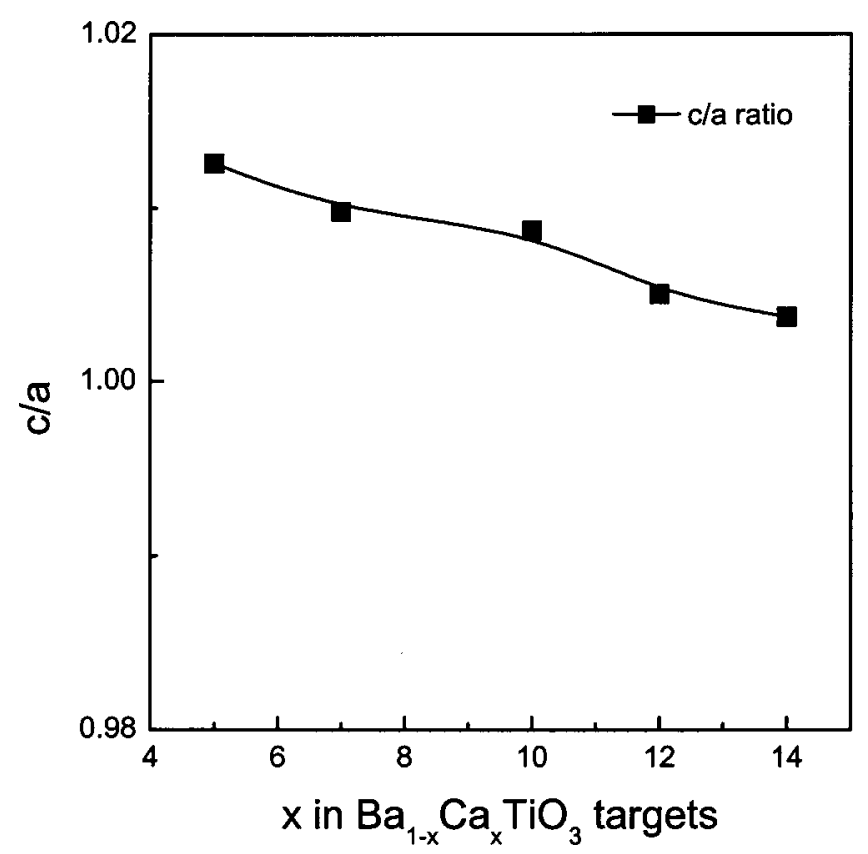

FIG. 2. The calculated $c / a$ ratio as a function of $x$ in $\mathrm{Ba}_{1-x} \mathrm{Ca}_{x} \mathrm{TiO}_{3}$ targets. 


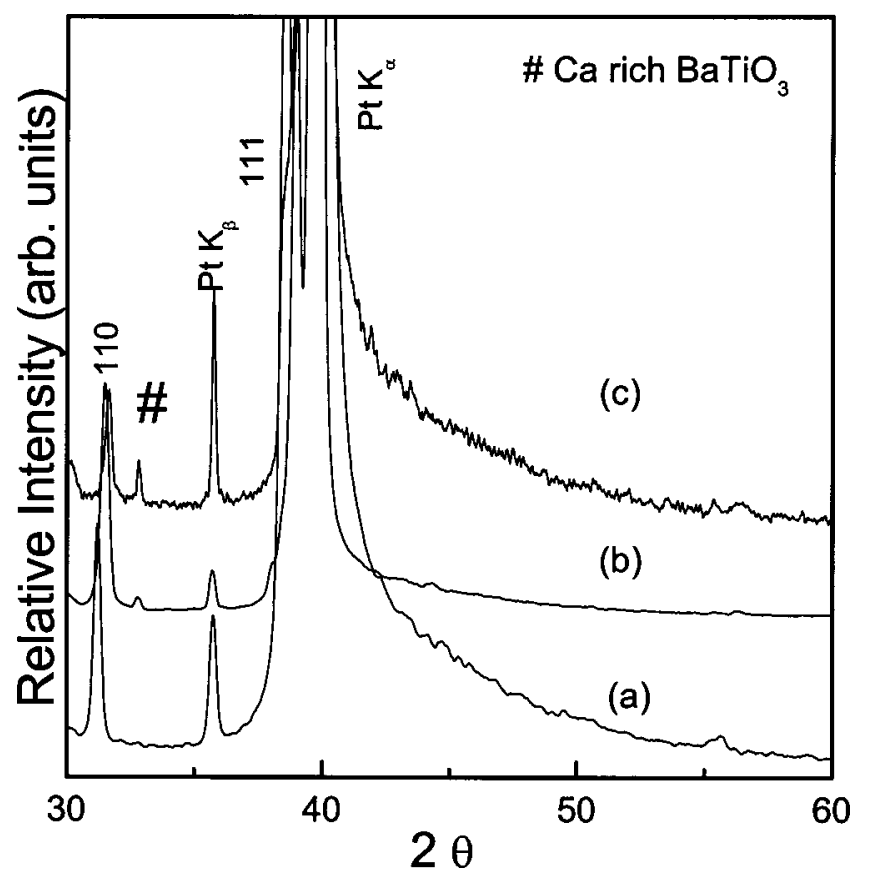

FIG. 3. The XRD of the BCT thin films deposited on $\mathrm{Pt}(111)$-coated $\mathrm{Si}$ substrate: (a) 5 at. $\% \mathrm{Ca}$-doped $\mathrm{BaTiO}_{3}$, (b) 12 at. $\% \mathrm{Ca}$-doped $\mathrm{BaTiO}_{3}$, and (c) 15 at. $\% \mathrm{Ca}$-doped $\mathrm{BaTiO}_{3}$ thin films.

higher Ca concentrations and is in accordance with the XRD pattern of BCT targets. Figures 4(a) and 4(b) shows the SEM micrographs of BCT5C and BCT12C thin films grown at 100 mTorr with $T_{\text {sub }}=700^{\circ} \mathrm{C}$. The surface morphology of micrographs shows significant faceted growth orientation along (111), with little orientation along (110), for the present given deposition conditions and is evident from our XRD pattern (Fig. 3). The cross-sectional view of the BCT12C thin films is shown in Fig. 4(c), and display mostly a columnar structure with little presence of the other planes, and the grains size varies from 45 to $80 \mathrm{~nm}$ exhibiting well defined densely packed grains. The three-dimensional tetrahedronlike structures are observed in the deposited BCT thin films as shown in Figs. 4(a) and 4(b) and a detailed study has not been carried out. The thickness of the thin films varied from 500 to $800 \mathrm{~nm}$ as measured by thin-film thickness monitor system (Filmetrics) and stylus method (Dektek). Figure 5 shows the SIMS profile of BCT12C thin films showing that the distribution of the elements is found to be uniform across the film and the interface at the film-Pt is sharper without any interdiffusion. These results establish that the grown thin films were of excellent quality.

\section{B. Dielectric studies}

The dielectric constant $\left(\epsilon^{\prime}\right)$ was observed to decrease with an increase in the $\mathrm{Ca}$ concentration of $\mathrm{Ba}_{1-x} \mathrm{Ca}_{x} \mathrm{TiO}_{3}$ ceramics and, likewise, the phase transition temperature also correspondingly decreased. The dielectric constant $\left(\epsilon^{\prime}\right)$ and $\tan \delta$ dependence on the temperature for the ferroelectric phase from the tetragonal to cubic phase at varied measuring frequencies on different BCT targets are shown in Figs. 6(a) and 6(b). The $\tan \delta$ is also found to peak near the phase transition temperature as observed in the $\epsilon^{\prime}-T$ and exhibit a
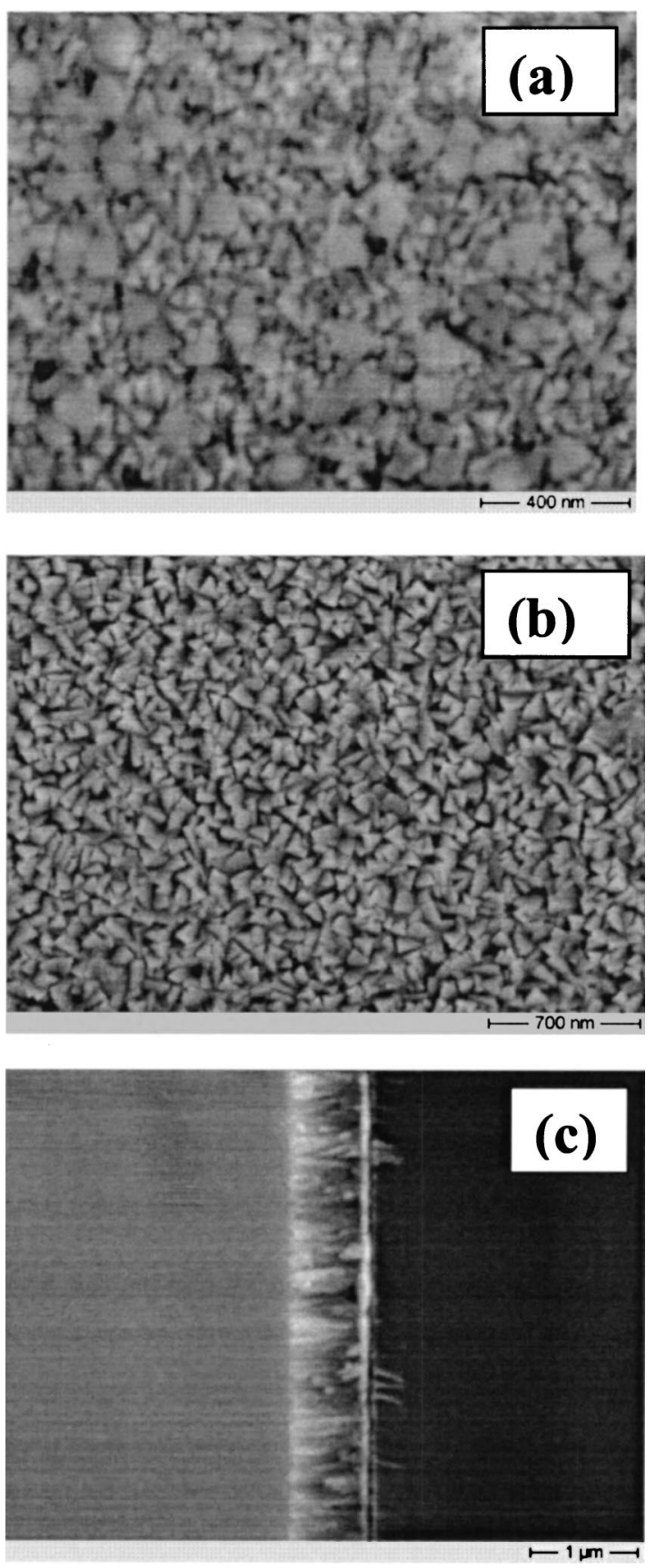

FIG. 4. (a) and (b) show the SEM micrographs of BCT5C and BCT12C thin films, respectively, grown at 100 mTorr with $T_{\text {sub }}=700^{\circ} \mathrm{C}$. (c) The crosssectional view of the $\mathrm{BCT} 12 \mathrm{C}$ thin films.

sharper phase transition, even for higher $\mathrm{Ca}^{2+}$ ions substituting in the $\mathrm{Ba}^{2+}$ site of BCT targets. This observed behavior is in accordance with the Kramers-Kronig relationship. Mitsui and Westphal ${ }^{17}$ also reported the existence of the sharper ferroelectric to paraelectric phase transition temperature for $\mathrm{Ba}_{1-x} \mathrm{Ca}_{x} \mathrm{TiO}_{3}$ ceramics $\left(x<20\right.$ at. \%). Pandey et al. ${ }^{18}$ observed a diffuse phase transition for higher calcium concentration in the barium titanate ceramics and attributed it to the purity of processing condition of ceramics and observed to be highly route dependent. The dielectric constant and tan $\delta$ dependence on the temperature of BCT5C and BCT12C thin films are shown in Figs. 7(a) and 7(b). The phase transition was sharper for BCT5C thin films $\left(T_{c} \sim 178 \mathrm{~K}\right.$ and $\sim 272 \mathrm{~K}$ 


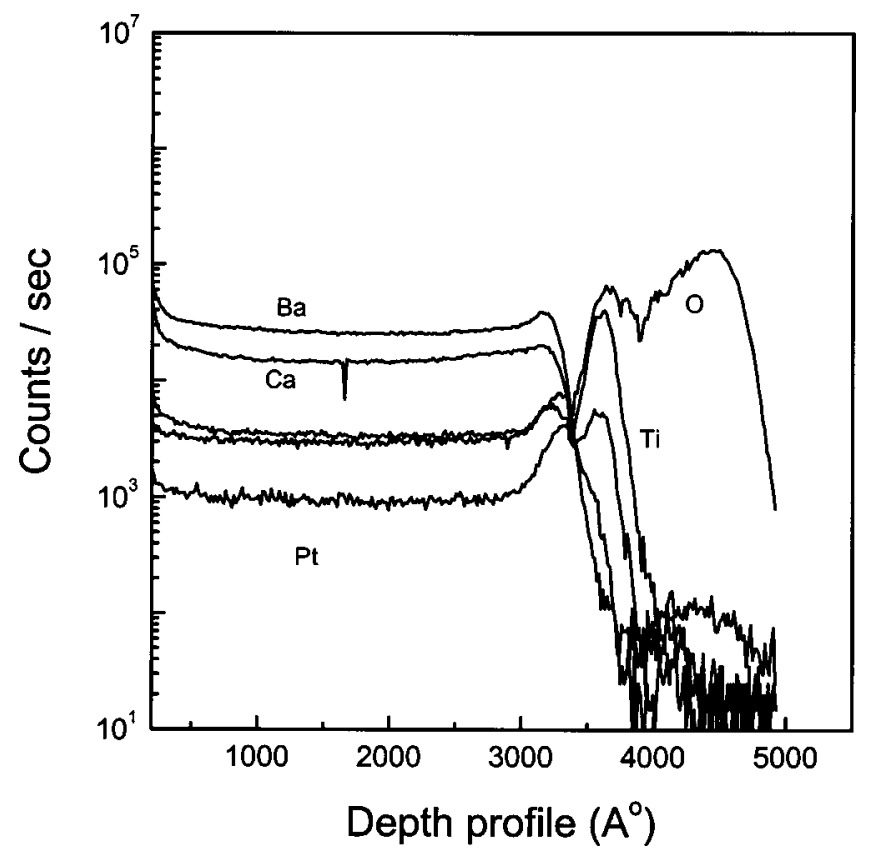

FIG. 5. The SIMS profile of BCT12C thin films showing the distribution of the elements to be uniform across the film and the interface of film-Pt/Si substrate.

at $1 \mathrm{kHz}$ ), while a diffuse phase transition behavior was observed for the BCT12C thin films $\left(T_{c} \sim 268\right.$ at $\left.1 \mathrm{kHz}\right)$. A similar diffuse phase transition behavior trend was also observed for higher $\mathrm{Ca}$ content $\left(\mathrm{Ca}>9\right.$ at. \%) in $\mathrm{BaTiO}_{3}$ thin films. In all laser ablated BCT thin films, there was an anomalous decrease in the phase transition temperature as opposed to the observed bulk phase transition temperature. In the case of the BCT12C thin films, the dielectric constant showed a broad maximum and the $T_{c}$ peak in $\tan \delta$ was significantly lower than observed in $\epsilon^{\prime}$ as shown in Fig. 7(b). The phase transition behavior in BCT12C thin films exhibited the signature of the typical diffuse phase transition behavior, i.e., relaxor-type behavior. In general, the decrease in the phase transition temperature is attributed to several reasons, such as integranular stresses, ferroelectric domain sizes,${ }^{19}$ interface between the substrate thin film, possibility of $\mathrm{Ca}^{2+}$ occupancy in the $\mathrm{Ti}^{4+}$ site, and compositional inhomogenity. In our case, the grain size effects have been ignored as the grain size in our grown thin films was quite large $(\sim 45 \mathrm{~nm}$ to $80 \mathrm{~nm})$ and the only possibility for the decrease in the $T_{c}$ is the occupancy of $\mathrm{Ca}^{2+}$ in the $\mathrm{Ti}^{4+}$ site and is dealt with in detail in Sec. IV. The $\tan \delta$ versus temperature plot is shown in Fig. 7(a) and it shows two distinct phase transition peaks observed in BCT5C thin films. The lower phase transition temperature $\left(T_{c} \sim 178 \mathrm{~K}\right)$ can be due either to the transition from the rhombohedral to tetragonal phase directly unlike the $\mathrm{BaTiO}_{3}$ in the same temperature regime, has the phase transition from the rhombohedral to orthorhombic phase or the lower phase transition can also be from the rhombohedral to orthorhombic phase and the second phase transition to follow can be the coexisitence of the tetragonal and orthorhombic phases. Beyond the second phase transitions, there is no phase transition behavior been observed. These investigations are to be carried out in detail
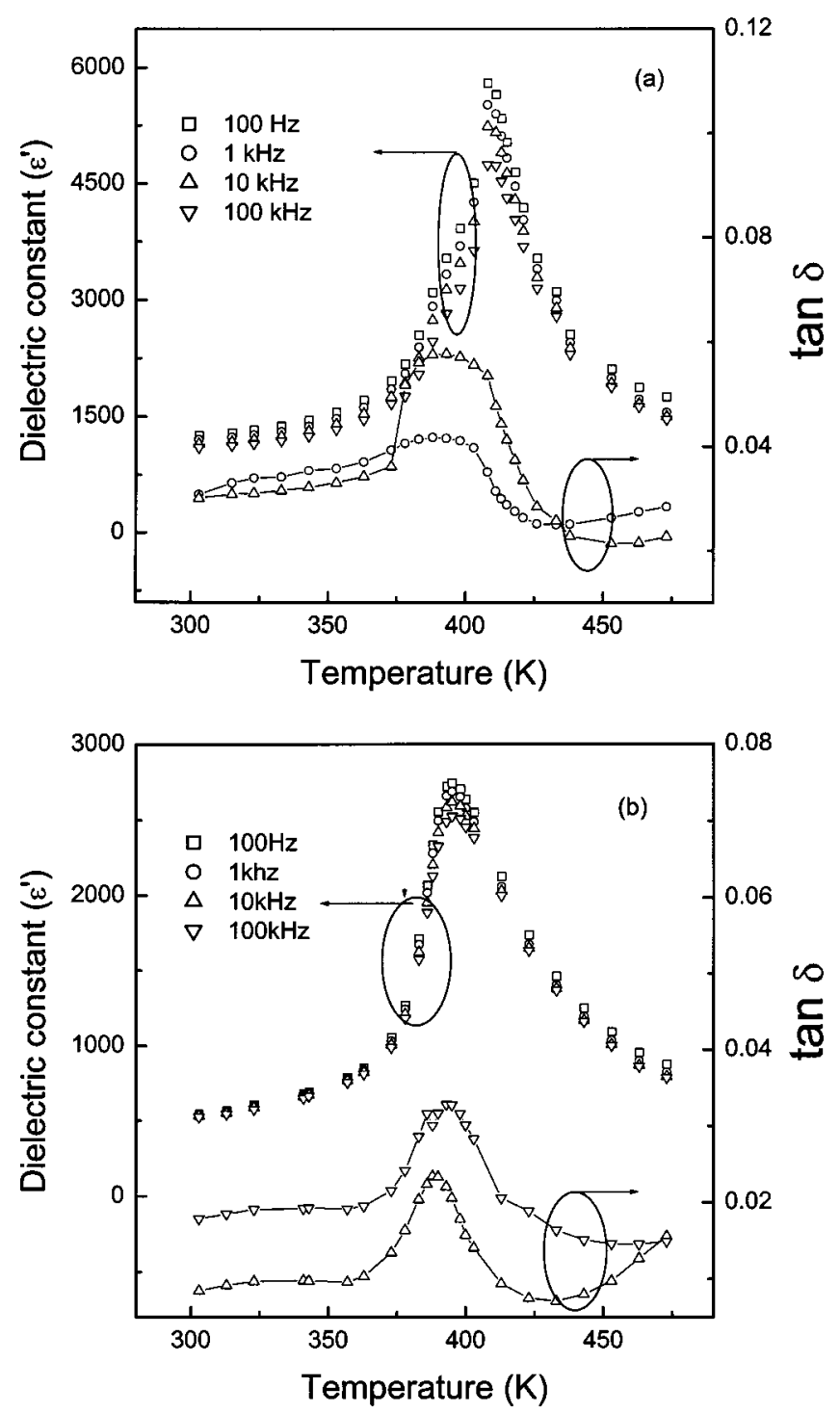

FIG. 6. (a) and (b) The dielectric constant and the $\tan \delta$ vs temperature of $\mathrm{Ba}_{0.95} \mathrm{Ca}_{0.05} \mathrm{TiO}_{3}$ and $\mathrm{Ba}_{0.90} \mathrm{Ca}_{0.10} \mathrm{TiO}_{3}$ targets, respectively.

and are not discussed in this article. The lower phase transition temperature for BCT12C thin films is not clearly seen and its diffuse phase transition behavior is relaxor type. The dielectric response of the relaxor ferroelectric is modeled as a response of an ensemble of the relaxors with a spectrum of the relaxation times. These are observed irrespective of the physical nature of these relaxators, exhibiting a broad maximum in the temperature dependence of $\epsilon^{\prime}$, with the relaxation dispersion around and below $T_{m}$. This type of behavior is attributed to the temperature evolution of this spectrum and the strong expansion of the spectrum occurs at a certain temperature $T_{f}$. All of the $\epsilon^{\prime}(T)$ curves measured at various frequencies namely show the reduction of the $\epsilon_{\max }$ and shift of the corresponding temperature $T_{m}$ with an increase in frequency. This observed behavior are the distinct features of the relaxors. The accountability of DPT behavior in the BCT12C thin films is dealt in detail as follows.

Assuming the distribution of the local transition temperatures of microregions in a diffuse phase transition material, with microscopic compositional fluctuations and on as- 

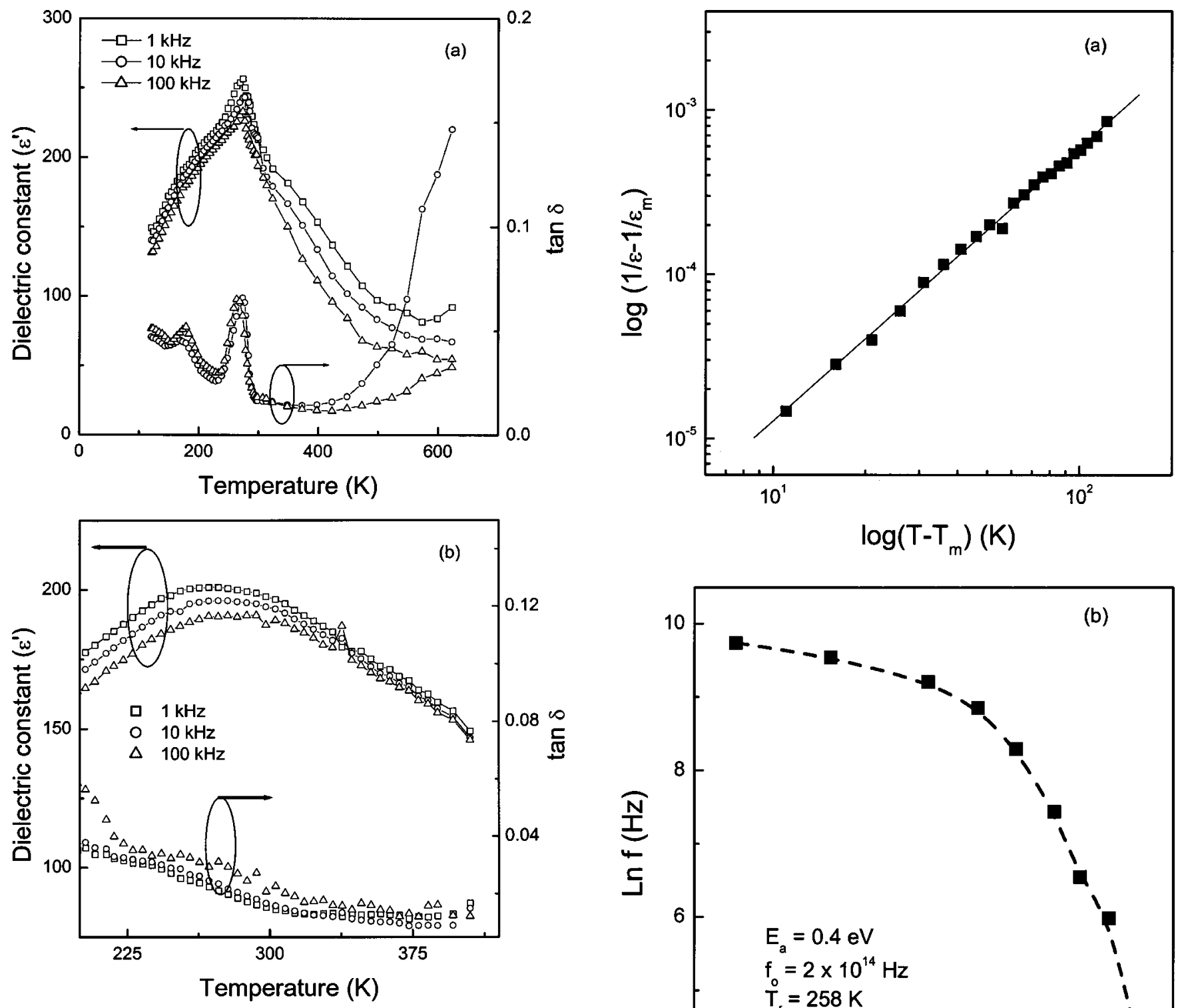

FIG. 7. (a) and (b): The dielectric constant and the $\tan \delta$ dependence on the temperature of the BCT5C and $\mathrm{BCT} 12 \mathrm{C}$ thin films.

suming it to be Gaussian around the mean Curie point $T_{m}^{\prime}$, Kirillov and Isupov ${ }^{20}$ have shown that the

$$
\left(\frac{1}{\epsilon^{\prime}-\epsilon_{\infty}}\right)=\left(\frac{1}{\epsilon_{m}^{\prime}}\right) \exp \left(\left(T-T_{m}^{\prime}\right) 2 \delta^{2}\right)
$$

with $2 \delta$ is the width of the Gaussian and determines the extent of diffuseness of the phase transition. If $\epsilon^{\prime} \gg \epsilon_{\infty}$, then, in series expansion, higher than second order can be neglected yielding $\gamma=2$. The limiting values $\gamma=1$ and $\gamma=2$ reduce expression (1) to the Curie-Weiss law valid for the case of a normal ferroelectric and the quadratic dependence (relaxor), respectively. The quadratic dependence of $1 / \epsilon^{\prime}$ on temperature has been claimed to be obeyed by several materials with diffuse phase transition behavior. The $\gamma$ value was obtained from the least-squares fit of $\ln \left((1 / \epsilon)-\left(1 / \epsilon_{m}^{\prime}\right)\right)$ versus $\ln \left(T-T_{m}^{\prime}\right)$ plots and is shown in Fig. 8(a) and the calcu-

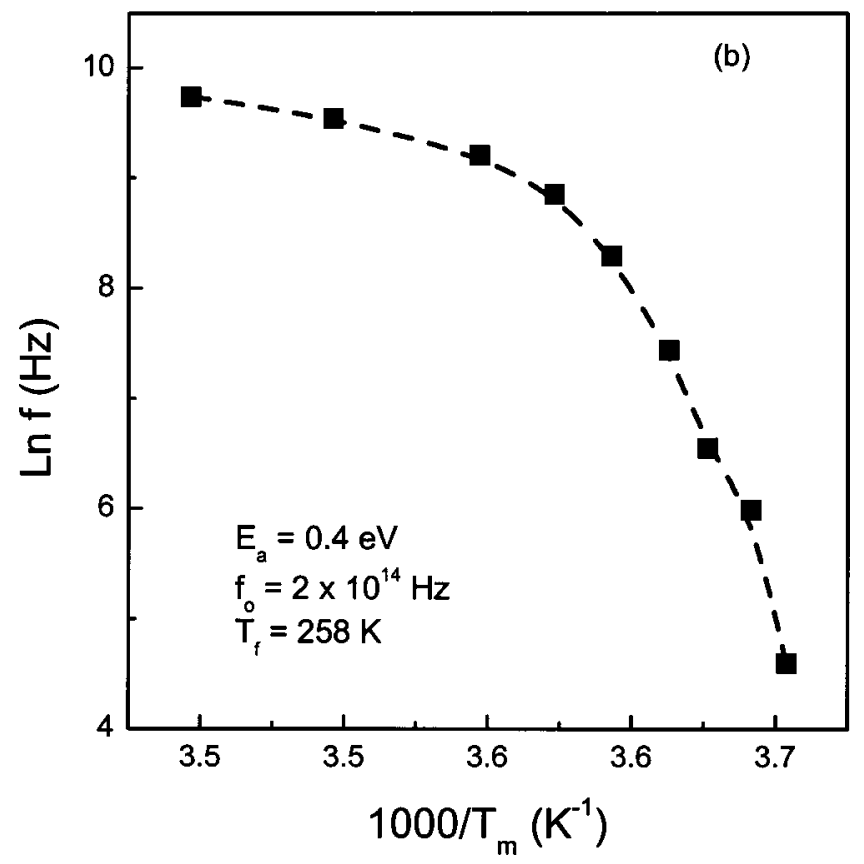

FIG. 8. (a) The plot of $\ln \left((1 / \epsilon)-\left(1 / \epsilon_{m}^{\prime}\right)\right)$ vs $\ln \left(T-T_{m}^{\prime}\right)$ to determine $\gamma$ value for the BCT12C thin films. (b) Frequency dependence of $T_{m}$ for BCT12C thin films. The symbols and solid line indicate data points and fit to VogelFulcher relationship, respectively.

lated $\gamma$ value is 1.78 for the $\mathrm{BCT} 12 \mathrm{C}$ thin films. The diffuseness of the phase transition can be described by an empirical parameter $^{21-23}$

$$
\Delta T_{\text {diff }}=T_{0.9 \epsilon}(100 \mathrm{~Hz})-T_{\epsilon m}(100 \mathrm{~Hz}),
$$

i.e., the difference between $T_{0.9 \epsilon}(100 \mathrm{~Hz})$ (the temperature corresponding to $90 \%$ of the maximum dielectric constant $\left(\epsilon_{m}\right)$ in the high-temperature side) and $T_{\epsilon m}$ (maximum $\epsilon^{\prime}$ at a temperature for $100 \mathrm{~Hz}$ ). The calculated diffuseness $\Delta T_{\text {dif }}$ for the BCT12C thin films is $70 \mathrm{~K}$. On the other hand, the degree of relaxation behavior can be described by a parameter 


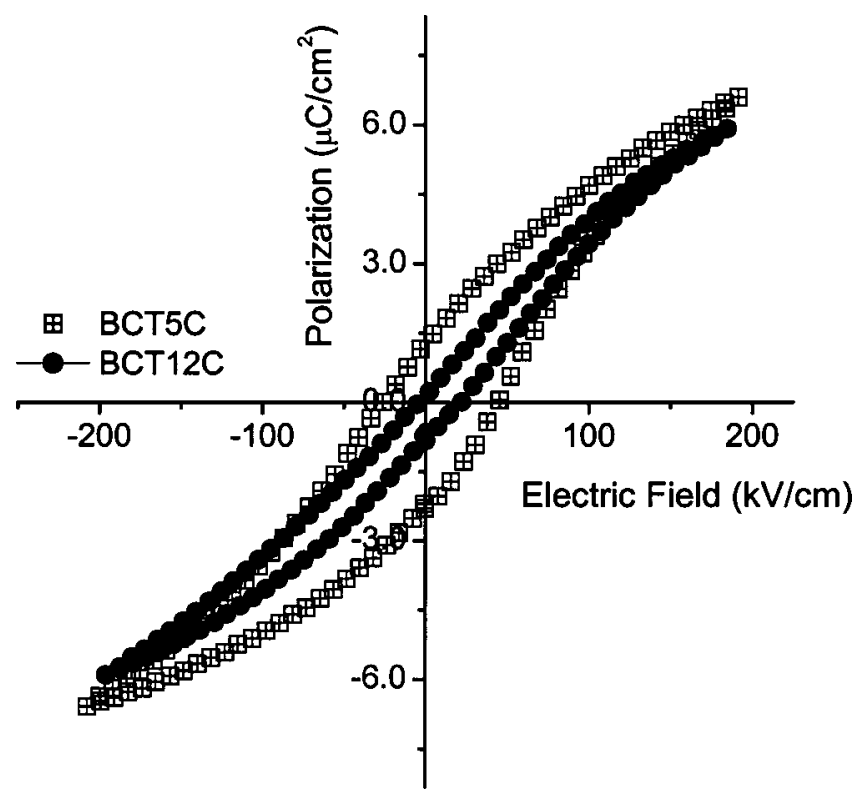

FIG. 9. The $P-E$ field curves of BCT5C and BCT12C thin films measured at $260 \mathrm{~K}$

$$
\Delta T_{\text {relax }}=T_{\epsilon m}(100 \mathrm{kHz})-T_{\epsilon m}(100 \mathrm{~Hz}),
$$

with $T_{\epsilon m}(100 \mathrm{kHz})$ and $T_{\epsilon m}(100 \mathrm{~Hz})$ denotes the temperature at which maximum $\epsilon^{\prime}$ was measured at $100 \mathrm{kHz}$ and 100 $\mathrm{Hz}$, respectively. The degree of the relaxation behavior measured in BCT12C thin films was $10 \mathrm{~K}$.

The above empirical characterizations with the CurieWeiss law and the estimated parameters $\left(\Delta T_{\text {relax }}, \Delta T_{\text {diff }}\right.$, and $\gamma$ ) show that the $\epsilon$ of the BCT targets and BCT5C thin films follows the normal ferroelectric Curie-Weiss law. In the case of BCT12C thin films, the phase transition behavior at the $\epsilon_{\max }^{\prime}$, calculated parameters $\Delta T_{\text {diff }}$ and $\Delta T_{\text {relax }}$ show significant diffuseness of the phase transition and frequency dispersion. The $\gamma$ value is close to 2 for BCT12C thin films, implying that these thin films exhibit a typical relaxor behavior.

The frequency dependence of $T_{m}$ is shown in Fig. 8(b) in the form of $1 / T_{m}$ versus $\ln f$. The observed frequency dependence of $T_{m}$ was empirically evaluated using the VogelFulcher relationship, adopted from the theory of magnetic relaxation in spin-glass systems ${ }^{24}$ and is given as

$$
f=f_{o} \exp \left(-\frac{E_{a}}{k\left(T_{m}-T_{f}\right)}\right),
$$

where $E_{a}$ is the activation energy, $T_{f}$ is the freezing temperature of polarization fluctuations, and $f_{o}$ is the pre-exponential factor. The values of $E_{a}, T_{f}$, and $f_{o}$ obtained for our BCT12C thin films were $0.4 \mathrm{eV}, 257.8 \mathrm{~K}$, and $2 \times 10^{14} \mathrm{~Hz}$, respectively.

\section{Polarization and capacitance-voltage measurements}

Figure 9 establishes the signature of ferroelectricity in both the BCT5C and BCT12C thin films, obtained from the polarization-electric field $(P-E)$ curves measured at $260 \mathrm{~K}$. The spontaneous polarization of BCT5C and BCT12C thin

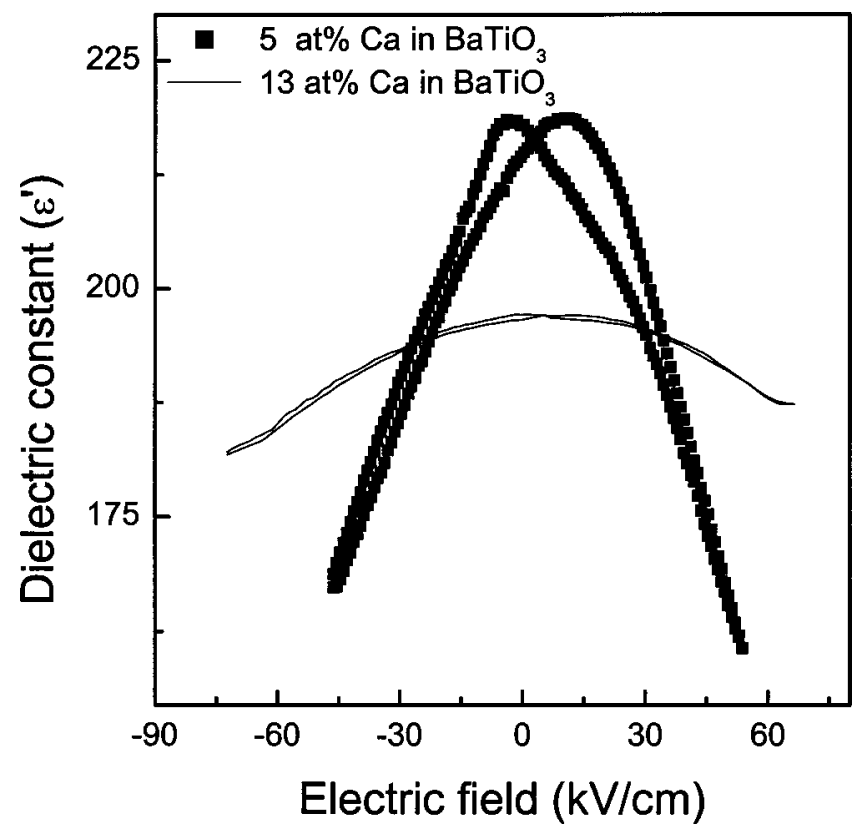

FIG. 10. The $C-V$ measurements of BCT thin films in MFM configuration measured at $260 \mathrm{~K}$.

films was found to be 6.8 and $5.8 \mu \mathrm{C} / \mathrm{cm}^{2}$, respectively, at $0.2 \mathrm{MV} / \mathrm{cm}$. The spontaneous polarization was found to decrease with the increase in the $\mathrm{Ca}$ concentration in $\mathrm{BaTiO}_{3}$ thin films. The $C-V$ measurements of BCT thin films are shown in the Fig. 10. A typical butterfly-shaped loop had been traced as seen in the $C-V$ curve for MFM configuration measured at $260 \mathrm{~K}$ and is consistent with that observed for ferroelectric thin films. The $C-V$ curve displays more diffusiveness for the BCT12C thin films signifying the presence of either compositional inhomogenity or strains between the films and substrate. The asymmetric loop in the $C-V$ curve may also be ascribed to the different types of electrodes $(\mathrm{Au} / \mathrm{BCT} / \mathrm{Pt})$ present at the both ends. The $C-V$ curve measured at $310 \mathrm{~K}$ exhibited a linear paraelectric behavior.

\section{Impedance spectroscopy}

The impedance spectroscopy plot provides insight into the types of carriers contributing to the conduction mechanisms. Figure 11 shows the impedance spectroscopy plot of BCT12C thin films and the inset shows the Arrhenius plot of resonant frequency versus 1000/T obtained from the impedance plot of BCT12C thin films. The calculated activation energy from the Arrhenius plot was $1.05 \mathrm{eV}$ and is attributed to the motion of the oxygen vacancies, ${ }^{25}$ which could have been created due to the substitution of $\mathrm{Ca}^{2+}$ ions in the $\mathrm{Ti}^{4+}$ site. $^{26}$

\section{DISCUSSION}

The possibility of an anomalous drastic decrease in the phase transition temperature of the BCT thin films has been attributed to the possibility of forcing $\mathrm{Ca}^{2+}$ ions to occupy the $\mathrm{Ti}^{4+}$ site, thereby introducing compressional stress in the lattice. $^{12}$ The laser ablated BCT thin films exhibited a drastic 


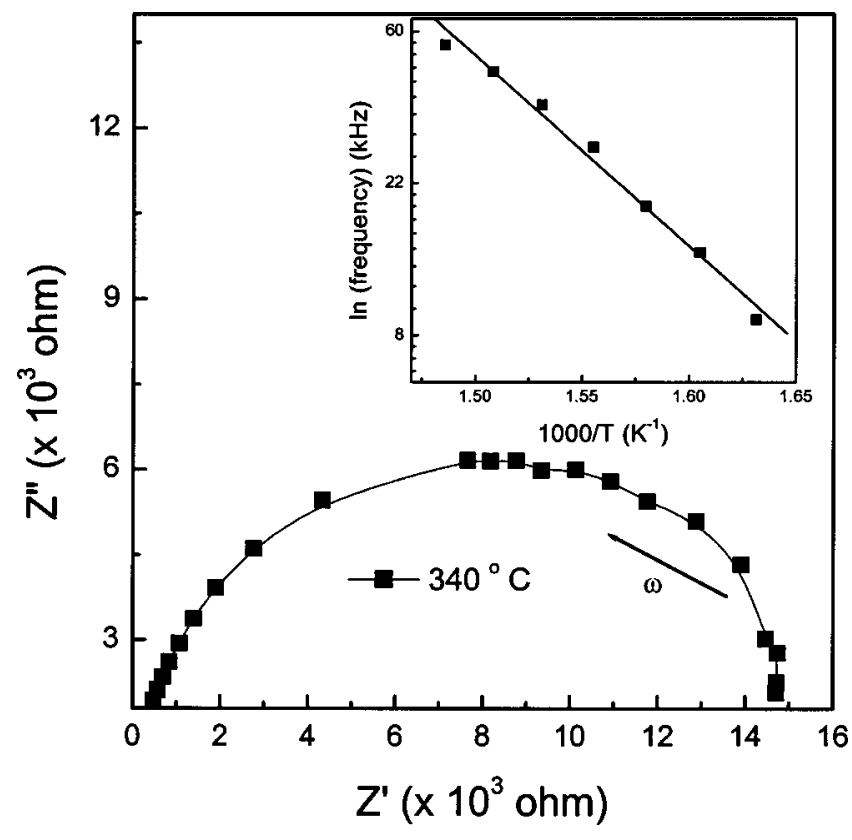

FIG. 11. Impedance spectroscopy plot of BCT12C thin films and the inset shows the Arrhenius plot of $f_{r}$ vs $1000 / T$.

decrease in the phase transition temperature to $285 \mathrm{~K}$ for BCT5C and, for higher $\mathrm{Ca}^{2+}$ ions $(x>0.09)$ occupying the $\mathrm{Ti}^{4+}$ site, results in a still lower $T_{c}$ and a broad diffused-type behavior. The diffuse phase transition was broad and appeared to be a relaxor type, which could have arose from either to the coexistence of the two phases in thermal equilibirium or the local compositional fluctuations arising from the excess $\mathrm{Ca}^{2+}$ ions occupying the $\mathrm{Ti}^{4+}$ site. There are earlier reports on the decrease of the dielectric phase transition temperature to $293 \mathrm{~K}$ for $\mathrm{Ba}_{0.95} \mathrm{Ti}_{1-x} \mathrm{Ca}_{0.05+x} \mathrm{O}_{3+x}(x$ $=0.05)$ ceramics and $320 \mathrm{~K}$ for the $\mathrm{BaTi}_{1-y} \mathrm{Ca}_{y} \mathrm{O}_{3-y}(y$ $=0.05)^{27}$ ceramics. The occupancy of $\mathrm{Ca}^{2+}$ ions either in the $\mathrm{Ba}^{2+}$ or $\mathrm{Ti}^{4+}$ site of $\mathrm{BaTiO}_{3}$, results in the following. ${ }^{9,10}$

(1) The simple substitution of $\mathrm{Ca}^{2+}$ with $\mathrm{Ba}^{2+}$ does not generate a charged defect; i.e., $\mathrm{Ba}_{1-x} \mathrm{Ca}_{x} \mathrm{TiO}_{3}$.

(2) Hans et al. ${ }^{10}$ and Zhang et al. ${ }^{11}$ suggested that in case $\mathrm{Ca}^{2+}$ substitutes for $\mathrm{Ti}^{4+}$ in the $\mathrm{BaTiO}_{3}$ lattice, it will act as an acceptor to trap the unlocalized electrons. It gives rise to a doubly charged acceptor center $\mathrm{Ca}_{\mathrm{Ti}}^{\prime \prime}$, which compensates for the oxygen vacancies formed [Eq. (5)], during sintering in a reducing atmosphere and results in the formation of high resistivity dielectrics; i.e., $\mathrm{BaTi}_{1-x} \mathrm{Ca}_{x} \mathrm{O}_{3-x}$,

$$
\mathrm{BaO}+\mathrm{CaO} \rightarrow \mathrm{Ba}_{\mathrm{Ba}}+\mathrm{Ca}_{\mathrm{Ti}}^{\prime \prime}+2 O_{o}+V_{o} .
$$

The possibility of the $\mathrm{Ca}$ in interstitials has been excluded as these defects are unlikely.

An alternative general equation for the incorporation reactions is summarized as follows

$$
\begin{aligned}
\mathrm{CaO}+ & (1-y) \mathrm{BaO}+y \mathrm{TiO}_{2} \\
\rightarrow & (1-y) \mathrm{Ba}_{\mathrm{Ba}}+y \mathrm{Ca}_{\mathrm{Ba}}+y \mathrm{Ti}_{\mathrm{Ti}}+(1-y) \mathrm{Ca}_{\mathrm{Ti}}^{\prime \prime} \\
& +(2+y) O_{o}+(1-y) V_{o} .
\end{aligned}
$$

The limiting cases for $y=1$ and $y=0$ correspond to the incorporation solely on the $\mathrm{Ba}$ or $\mathrm{Ti}$ sites, respectively. In the case of $\mathrm{Ca}^{2+}$ substituting for $\mathrm{Ti}^{4+}$ ions in the $\mathrm{BaTiO}_{3}$ thin films, it results in a compositional and structural disorder due to the symmetry breaking. This is brought about by the difference in valences $(4+$ versus $2+)$ and ionic radii $(0.69$ versus $00.99 \AA$ ) which is believed to be responsible for the relaxor behavior and result in the drastic decrease in $T_{c}$ behavior. The cross over from the ferroelectric to diffuse phase transition arises when the higher composition of the Ca content enters the $\mathrm{B}$ site $\left(\mathrm{Ti}^{4+}\right)$ disrupting the dipoles, creating the higher degree of disorder, and eventually inducing relaxor behavior. Such behavior introduces structural randomness, lattice defects, lattice strains, and altered forces. The symmetry breaking occurs at the nanometer scale leading to the formation of polar nanodomains and increases in size upon cooling, but never become large enough to precipitate a long-range-ordered ferroelectric state. ${ }^{28}$ The activation energy obtained from the impedance spectroscopy plot is 1.05 $\mathrm{eV}$ and is attributed to the oxygen vacancy motion, which could have been created due to Ca occupying the Ti site as shown in Eq. (5). This also further confirms that the oxygen vacancy is present in these thin films, which could have resulted from the substitution of $\mathrm{Ca}^{2+}$ in the $\mathrm{Ti}^{4+}$ site. $P-E$ and $C-V$ curves further confirm that these BCT thin films are ferroelectric in nature below the observed $T_{c}$.

\section{CONCLUSIONS}

$\mathrm{Ba}_{1-x} \mathrm{Ca}_{x} \mathrm{TiO}_{3}$ targets were prepared by a conventional solid-state reaction technique and the thin films were deposited on Pt-coated $\mathrm{Si}$ substrates by a pulsed excimer laser ablation technique. The anomalous drastic decrease in $T_{c}$ was attributed to the substitution of $\mathrm{Ca}^{2+}$ ions in the $\mathrm{Ti}^{4+}$ site. The dielectric constant and dielectric phase transition temperature of the target and thin films was observed to decrease with an increase in the calcium content. There was a significant cross over observed from the normal ferroelectric to diffuse phase transition behavior on the substitution of the higher $\mathrm{Ca}^{2+}$ ions in the $\mathrm{Ti}^{4+}$ site.

\section{ACKNOWLEDGMENTS}

One of the authors (P.V.) wishes to acknowledge the CSIR, India for the research fellowship (CSIR-SRF) and Professor George Samara, Sandia National Laboratory, USA and Professor T. R. N. Kutty, Materials Research Center, Indian Institute of Science, Bangalore, India for their valuable discussions.

${ }^{1}$ A. I. Kingon, S. K. Streiffer, C. Basceri, and S. R. Summerfelt, MRS Bull. 21, 46 (1996).

${ }^{2}$ O. Auciello, J. F. Scott, and R. Ramesh, Phys. Today 51, 22 (1998).

${ }^{3}$ D. L. Polla and L. F. Francis, MRS Bull. 21, 59 (1996).

${ }^{4}$ Y. Sakabe, T. Takagi, K. Wakino, and D. M. Smith, Advances in Ceramics, edited by J. B. Blum and W. R. Cannon (Am. Ceram. Soc. Inc., Ohio, 1986), Vol. 19, p. 103.

${ }^{5}$ F. J. Walker and R. A. McKee, Nanostruct. Mater. 7, 221 (1996).

${ }^{6}$ H. Veenhuis et al., Appl. Phys. B: Lasers Opt. 70, 797 (2000).

${ }^{7}$ P. Gunter and J. P. Huignard, eds., Photorefractive Materials and their Applications II, Topics in Applied Physics, Vol. 62 (Springer, Berlin, 1989). 
${ }^{8}$ P. Victor, R. Ranjith, A. Sarkar, R. Vinayak, S. Saha, and S. B. Krupanidhi, Proceedings of the Materials Research Society, Boston, MA, Fall 2002, p. U 12.5 .

${ }^{9}$ T. F. Lin, J. L. Lin, C. T. Hu, and I. N. Lin, J. Mater. Sci. 26, 491 (1991).

${ }^{10}$ M. Y. Chul Chang and S. C. Yu, J. Mater. Sci. Lett. 19, 1323 (2000).

${ }^{11}$ V. S. Tiwari, D. Phandey, P. S. R. Krishna, R. Chakravarthy, and B. A. Dasananacharya, Physica B 172, 112 (1991).

${ }^{12}$ Y. H. Han, J. B. Appleby, and D. M. Smyth, J. Am. Ceram. Soc. 70, 96 (1987).

${ }^{13}$ X. W. Zhang, Y. H. Han, M. Lal, and D. M. Smyth, J. Am. Ceram. Soc. 70, 100 (1987).

${ }^{14}$ Hennings and Schereimacher.

${ }^{15}$ Z. Q. Zhuang, M. P. Harmer, D. M. Smyth, and R. E. Newnham, MRS Bull. 22, 1329 (1987).

${ }^{16}$ D. Y. Kim, S. G. Lee, Y. K. Park, and S. J. Park, Jpn. J. Appl. Phys., Part 2 34, L1516 (1995).
${ }^{17}$ T. Mitsui and W. B. Westphal, Phys. Rev. 124, 1354 (1961).

${ }^{18}$ V. S. Tiwari, N. Singh, and D. Pandey, J. Am. Ceram. Soc. 77, 1813 (1994).

${ }^{19}$ T. M. Shaw, S. Trolier-McKinstry, and P. C. McIntyre, Annu. Rev. Mater. Sci. 30, 263 (2000).

${ }^{20}$ V. V. Kirilov and V. A. Isupov, Ferroelectrics 5, 3 (1973).

${ }^{21}$ K. Uchino and S. Nomura, Ferroelectr. Lett. Sect. 44, 55 (1982).

${ }^{22}$ G. A. Smolenskii and A. I. Agranovskya, Sov. Phys. Tech. Phys. 3, 1380 (1958).

${ }^{23}$ Z. Yu, C. Ang, R. Guo, and A. Bhalla, J. Appl. Phys. 92, 2655 (2002).

${ }^{24}$ H. Vogel, Phys. Z. 22, 645 (1921).

${ }^{25}$ R. Waser, J. Am. Ceram. Soc. 74, 1934 (1991).

${ }^{26}$ P. Victor, R. Ranjith, A. Sarkar, and S. B. Krupanidhi (unpublished).

${ }^{27}$ J. G. Park, T. S. Oh, and Y. H. Kim, J. Mater. Sci. 27, 5713 (1992).

${ }^{28}$ G. A. Samara and L. A. Boatner, Phys. Rev. B 61, 3889 (2000). 